\title{
Coworking spaces: An exploratory study to identify the challenges and different business models in Egypt
}

\author{
Safaa Maher \\ Passent Tantawi \\ Mohamed A. Ragheb \\ Arab Academy for Science, Technology and Maritime Transport, Egypt \\ Graduate School of Business
}

\begin{abstract}
Keywords
Coworking space, flexible offices, challenges, business model.
\end{abstract}

\begin{abstract}
The focus of this research is in the area of co-working spaces. Such a study is important in order to enhance the understanding of the growth of co-working spaces in Egypt. Coworking spaces as startups have seen wide expansions worldwide in conjunction with the evolution of the shared economy, start-ups, and entrepreneurial projects and the labor market trends of freelancers and part-time employees. The research approach adopted in this paper is a qualitative approach. Semi structured interviews were conducted with a convenient sample of coworking space managers or founders in Cairo and Alexandria, the main two cities in Egypt which have the largest number of coworking spaces. The interviews aimed to explore their practices, choice of business model adopted among several ones to generate revenue and the challenges faced in running the coworking space. Thus, the questions focused on asking the interviewees to explain the business model adopted by the space as well as the services and networking they provide in addition to the challenges they face in running the business successfully. The findings in this paper revealed that coworking spaces in Egypt are constantly modifying their business model to adjust to market conditions in order to achieve profitability. Thereby, coworking spaces are still in their infancy stage and are subject to many changes and evolutions to meet the market trends. Furthermore, the financial viability and profitability are at stake and founders are adjusting their services and pricing accordingly. Among other results, high employee turnover was highlighted frequently by the managers during their interviews. The academic contribution relies in adding to the coworking space literature with respect to challenges faced in developing countries. The practical implications of this research offer actionable knowledge for coworking space managers and founders to provide the services and activities that would attract their target user and increase their loyalty to the space since users such as small companies have different needs from freelancers and part-time employees.
\end{abstract}

\section{The Introduction}

Over the last decade, the coworking space as a startup business model has witnessed exponential growth around the globe implying becoming the 'new model of work' in the setting of the 'collaborative and 'sharing' economy (Botsman and Rogers, 2011). Thus, changes in both economic and market dynamics such as favoring outsourcing and subcontracting, associated with global computing, encouraging the growth of micro-enterprises, self-employed and freelance knowledge workers created demand for this service (Moriest,2014). This global exponential growth of coworking spaces was estimated to reach 20,000 in 2019 and 25,968 by 2022 (Coworking Resources, 2019). The core benefit for users resides in the notion that independent professions and those with workplace flexibility work better together than they do alone.

Across the Middle East region, coworking space has started to infuse the market with the foundation of AstroLabs in Dubai and KSA, Emaar's e25, Dtech, A4 Space, Youth x Hub and DIFC's Fintech Hub. Up till now, flexible office space represents less than $1 \%$ of the region's office stock, while there are still opportunities in the market for mega international players (Deloitte, 2019). On a national level, in Egypt the concept started in the capital city of Cairo in 2007. A non-profit initiative titled Rasheed 22 was launched by a German lady whose main driver was to provide a place to work that indorsed 
sharing and collaboration. Other coworking venues followed such as District Spaces, founded in 2011 then 302Labs, Almaqarr, IceCairo, and Startup Haus Cairo (American Chamber, 2018).

The total exact number of coworking spaces in Egypt is unknown, since a growing number of businesses are currently opening coworking 'sections' within their activities, or as a separate business model without formally registering as coworking spaces. The cities of Cairo and Alexandria have the largest number of coworking spaces in Egypt. Nonetheless, smaller cities such as Gouna, Mansoura and Assuit scored the highest in relation to the coworking spaces to population ratio. In other words, the number of coworking spaces per capita is higher in smaller cities than in large ones (Enpact, 2019).

Egypt is one of the largest startup hubs in the Arab World since the Egyptian government has prioritized the promotion of entrepreneurship in the past few years. In the field of entrepreneurship, a startup ecosystem is formed by entrepreneurs, startups in their various stages, and numerous other entities such as universities, investors, accelerators, coworking spaces, legal and financial service providers, and government agencies.

Despite the important role of coworking spaces in regional development and their positive externalities (Research Group Collaborative Spaces, 2016), many of these spaces are financially vulnerable and challenged by the significant financial burden they face in terms of running and maintenance costs (Moriset, 2014; Research Group Collaborative Spaces, 2016). According to Deskmag (2019) only 40\% of coworking spaces are profitable. According to UNCTAD (2017) Egypt ICT policy indicated that there are grants offered to managers of the coworking spaces to extend their services by covering the core operating and managerial costs, including human resources, maintenance, rent, ICT infrastructure, communications, administration, capacity-building training, etc.

The theoretical foundation for this research setting is based on the social servicescape concept in design, environmental psychology, and service-marketing literature. The concept of the social servicescape was enhanced by Rosenbaum and Massiah (2011) as cited in Balakrishnan (2017) to embrace customer and employee interaction together in a consumption setting. This research builds as well on the Social Facilitation Theory which advocates that in realizing the social characteristic of the environment, the simple presence (or absence) of audiences have consequences for human behavior (Tombs \& McCollKennedy, 2010). There are abundant empirical studies with respect to the impact of social servicescape elements on restaurants, cafes, and hotels as research settings. However, comprehensive empirical studies on different settings are still required to enrich the social servicescape framework and in order to contribute to the development of the service marketing literature especially in a specific novel industry like coworking spaces.

Thus, the aim of this research is to advance an understanding of the coworking spaces conditions in Egypt through a qualitative approach that attempts to answer the following research questions: What are the different business models adopted? What activities and events take place in coworking space in Egypt? What challenges do the founders face in running coworking spaces?

This paper sections are structured as follows: section 2 discusses the literature on coworking spaces. Section 3 represents the research methodology. Section 4 discusses the findings. Section 5 entails the discussion and conclusion. Finally, section 6 presents the limitations and direction for future research.

\section{Literature Review}

The emergence of collaborative models of work thrived literature around the theme of coworking spaces, as scholars addressed it from both academics' and practitioners' perspectives. Co-working spaces started by 2005 in San Francisco as cited in (Moriset, 2014) it is a hosting, working and meeting place for entrepreneurs who are carriers of projects and ideas and wish to share them with others; this place is powered by a specific animation intended to create links inside and outside of the community of coworkers. Although current coworking spaces vary in terms of business model, size, specialization and amenities, most are founded to accommodate individuals or groups that are not necessarily employed by a single organization, however users share certain values and are interested in the synergies which may occur from working with like-minded people in the same space (Knoll, 2016).

The coworking space literature is rich with regards to coworking spaces topology and management models in USA, Europe and Far East (Huwart, Dichter and Vanrie, 2012; Bilandzic and Foth, 2013; Ressia, 2015; Rus and Orel, 2015; Leclercq-Vandelannoitte and Isaac, 2016). In addition some scholars studied the 
importance of value in use, customer satisfaction and behavior and loyalty patterns (Brierley, 2012; Rai and Srivastava, 2012; Fraering and Minor, 2013).

Capdevila (2014) conducted a qualitative study in Barcelona which examined the dynamics of innovation involving coworking spaces and found that managers of coworking spaces, have an influence in facilitating collaborative practices among co-workers. Gerdenitsch, Scheel, Andorfer and Korunka (2016) asserted a positive contribution of coworking spaces in Austria to the social support provided to independent professionals. Parrino (2015) observed an important role of organizational and social proximity in stimulating knowledge flows among co-workers, while controlling for geographical proximity. Other studies presented a broader framework of the role of coworking spaces in the city-level innovation ecosystem (Moriset, 2014; Mulas, Minges and Applebaum, 2015; Research Group Collaborative Spaces, 2016).

In the essence of coworking spaces being a player in the start-ups ecosystem, Balakrishnan (2017) empirical findings from the qualitative phase revealed management support services provided by the coworking space enable the coworking members to operate their businesses efficiently. Huwart et al. (2012) highlighted that it is not just a workplace; it is more than sharing desks. Like-minded people get together, creating synergies, creative \& energetic spots, innovators interact, share, build, co-create projects, and managers thrive to maintain a positive creative climate. In Egypt, coworking spaces do not only provide the physical space, but also host a lot of educational events such as workshops on entrepreneurship, finance, HR, and how to launch a business (American Chamber, 2018).

Investing in a coworking space may seem attractive due to the ease of entry, but sustaining the business is difficult. The founders mostly faced problems with introducing concepts and marketing to the potential users during the foundation phase. The people who visited at the beginning did not understand what the space really was, getting mixed with cafe, educational center, or library. Founders and managers had to invest heavily to position themselves not only as a nice place to spend some time in, but also to be part of a creative community (ibid).

There are three or four successful business models for coworking spaces. Profits are often generated by renting desks, lockers, and conference rooms. The first business model for coworking spaces is the one that generates revenue from membership fees for renting a workspace; these fees can be calculated according to the time the users spend - daily, monthly, quarterly or annual fees that allow the member to use basic or more advanced amenities of the coworking space. Discounts are provided for longer memberships to reward loyalty or give group discounts to make profits off serving larger teams.

The second business model is based on renting amenities and equipment; amenities can include private audio or video call cabins, lockers, private offices with full equipment, mailboxes, kitchens and refrigerator rooms, as well as social spaces that can be rented for discounted fees to regular members. Equipment rentals can be like telephone lines, video, and audio equipment for the conference room, printers, computers, and even cloud storage for startups that need larger data resources.

The third business model is a membership package that includes collaborative business models with local amenities, for instance-food spots, bars and clubs, gym and fitness locations, outdoor activities, transportation discounts, medical assistance and alternative revenue sources that meet the needs of a member and that can be easily incorporated into the basic package. The fourth business model focuses on conference room rentals; adapting a conference room to serve multiple purposes. Conference rooms can be rented for business purposes, such as holding meetings, training staff, and video presentations, as well as for alternative social events.

A passionate investor with vision would set realistic pricing to succeed. Securing grants such as funds concentrated on supporting high-impact projects helps the coworking spaces to build their team and financially cover their operations (American Chamber, 2018).

\section{Research Methodology}

The aim of this research is to advance an understanding of the coworking spaces conditions in Egypt through a qualitative approach. Exploratory studies are undertaken to better comprehend the nature of the problem since very few studies might have been conducted in the Egyptian context. Extensive interviews with many people might have to be undertaken to get a handle on the situation and understand the phenomena. (Sekaran and Bougie, 2016). A semi structured interview (see appendix for 
questions) was conducted with coworking space managers/founders in Alexandria and Cairo. It aimed to answer the following research questions: What are the different business models adopted? What activities and events take place in coworking space in Egypt? What challenges do the founders face in running coworking spaces?

The study sample is a convenient sample which is one of the nonprobability sampling designs, the elements in the population do not have any probabilities attached to their being chosen as sample subjects. This means that the findings from the study of the sample cannot be confidently generalized to the population. It was matching the aim of the research to obtain some preliminary information in a quick and inexpensive way. Convenience sampling is most often used during the exploratory phase of a research project and is perhaps the best way of getting some basic information quickly and efficiently (ibid).

Thematic analysis was used to interpret the results of the interviews. It is a technique used for identifying, analyzing, and reporting patterns (themes) within collected data. It organizes and describes data set in detail. Apart from that, it interprets various facets of the research area. It provides an accessible and theoretically flexible approach for qualitative data analysis. Thematic coding is a method performed within major analytic researches (such as grounded theory), rather than a specific approach in its own sense (Braun and Clarke, 2006).

Under the sample of this study and according to the responses received from 11 participants, the following findings are explained in each section. The demographics of the research participants in respect to gender were 10 males and 1 female, age group was 25-35. All respondents hold a bachelor's degree.

The interviews were conducted face to face. The average duration was 45 minutes. The audio record was made after the participants' appraisal and agreement to participate in the study. All the participants answered the 15 questions and at the end of the interview, they were given the chance to ask any question about the research or any contribution they would like to add.

\section{Findings/results}

Following the thematic analysis of the conducted interviews with the managers/founders of coworking spaces, the following ten themes have emerged as detailed in the following sections:

\section{Theme 1: Business Models are changeable to meet the market needs:}

The coworking space (CS) owners mentioned that the main sources of revenues are room renting, training \& consultations and that their business model was changeable over time according to market dynamics and profitability issues. This was reflected in the comments:

"Our sources of revenue are room renting and workshops". (CS1, Manager)

"Our business model started as a student space then the business model has developed to be a high-level space equipped for entrepreneurs and start-ups as a private offices and as co-working slots for individuals. Also, we provide consultation services with other co-working spaces in Cairo, Damanhur, Qena, Luxor etc. Anyone who wants to open Coworking space consults us and we offer training services as well for an agreed upon fees". (CS2, Owner \& managing director)

"The business model was changing over time, as at first we were discovering the market as our model was restricted to studying area concept. In 2017, we participated in the best co-workspace in Egypt contest and we got the seventh rank. After the competition we started to develop our business model to include the following services: Recruitment programs and capacity building programs (We have received funding from civil society to train the youth more than 150 trainees), online learning programs, entrepreneurship programs as we gave a support to more than 20 projects, office rent and business consultation". (CS7, founder \& business developer)

\section{Theme 2: Customers vary according to the coworking space market niche:}

All responses regarding this question indicated that the coworking space attracts customers of the same category; in some places the main customers are students, while for others it is entrepreneurs and freelancers, the visitors age ranged from 16-45 years and the males represent the bigger portion of users as reflected in their responses. Below is an extract of the responses received in support of the aforementioned: 
"We target undergraduate students, so we have $90 \%$ mainly students, 10\% entrepreneur and freelancers". (CS3, Owner \& managing director)

"Our customers are mostly freelancers in ICT (developers, web designer, trainers)".

(CS5, Community manager)

"We target start-ups and small companies". (CS2, Owner \& managing director)

\section{Theme 3: The frequency of visiting varies with the type of customer}

Most of the respondents revealed that students and freelancers come on daily basis, while entrepreneurs visit on weekly basis as reflected in their comments:

"Our visit frequency depends on the customer's need, some come to attend trainings, students visit daily and freelancers, while entrepreneurs' usage is 2 days weekly".

(CS1, Manager)

Theme 4: Interaction between members rarely takes place

Most interviewees expressed that there is no interaction between the members, and this was reflected in the comments:

"Our users prefer privacy and isolation to concentrate on performing their tasks".

(CS1, Manager)

"In our coworking space the interaction between daily users is rare, but sometimes a user requests a graphic designer for example, our community manager guide him to the right one from our members". (CS4, Owner \& managing director)

\section{Theme 5: The community manager plays an important role to induce networking}

All respondents agreed that in order to foster networking and interaction among the users, the community manager has a strong role to play and this was reflected in the comments:

"In our coworking space, the community manager organizes events that increase the interaction among users who rent private offices". (CS2, Owner \& managing director)

"The activities organized by our community manager makes the visitors interactive".

(CS5, Community manager)

"A great percentage of our user interaction is dependent upon our community manager and our social activities and as a result there are users who got married, users partnered in projects, and there are users who found jobs and got employed by other users".

(CS7, founder \& business developer)

When asked about the activities taking place, the CSs owners/mangers mentioned that:

"Through our community manager organizing social events such as: Ramadan Holly month meal (Iftar), games night and movies night". (CS1, Manager)

"Through our special events like monthly meeting for personal development sessions like work life balance... etc. or monthly breakfast \& birthday parties for our members".

(CS2, Owner \& managing director)

Theme 6: Physical Design (Layout) promotes privacy, performance, and positive energy

Regarding the design and layout, the comments of the owners and managers revealed that the designs are meant to promote privacy, performance and spreading the positive energy as reflected in the comments:

"The decor was chosen to suit the tastes of the young people, comfortable chairs and desks that promote simplicity and encourage users to focus on their performance". (CS1, Manager)

"Our CS is divided into several sections to meet the different needs of our users; there are a number of private offices which contain: meeting tables or desks or both of them depending on customer desire, this suits start-ups and small business, then we have training or conference rooms, and of course a spacious space of work stations for daily users which has (sofas, partitions, shared tables, and bean bags)".

(CS7, founder \& business developer)

"Customized designs for companies which rent private offices is an option to tailor the design and colors according to their requests". (CS2, Owner \& managing director) 


\section{Theme 7: Customer satisfaction is contingent on the quality of amenities}

When the respondents were asked about the factors that the customers require in order to be satisfied; all responses indicated that coworking spaces conduct customer satisfaction surveys whether electronic, oral, or written in a periodic or non-periodic manner. In addition, most of the responses regarding the factors satisfying co-working space members were limited to amenities and finding a suitable place to be productive. These amenities are internet speed, comfortable furniture, air conditioning and strong lighting and this was reflected in the comments:

"value for money, business support through consultancy services, cleanliness, printers, scanners and internet speed". (CS5, Community manager)

"we measure our customer's satisfaction through our mobile application, as the client can rate us for the following items: place rules, payment plans, internet speed, and staff behavior and service quality". (CS2, Owner \& managing director)

\section{Theme 8: There is a variety of loyalty programs and discounts for loyal customers}

All responses indicated that coworking spaces offer their customers loyalty programs and discounts, this was reflected in the comments:

"we give daily user and freelancers $20-25 \%$ discount on the hour's bundles, offer flexible hours with no limit to duration or time range. For dissatisfied loyal customers, if the evaluation result is below average, we give the client $50 \%$ discount and if the evaluation result is poor, we give the client one day free". (CS2, Owner \& managing director)

"We provide discounted training courses for our loyal customers/frequent visitors. These training courses are conducted at our premises". (CS3, Owner \& managing director)

"We give points for our daily subscribers, discounts for specific services, \& vouchers. For our monthly subscribers we give them discounts on training courses, free tickets to attend business events. (CS5, Community manager)

"We offer publicity and business networking for our loyal users". (CS7, founder \& business developer)

\section{Theme 9: The major challenges are low financial return and high employee turnover}

Most respondents revealed that the sustainability of the business is at stake as the financial return and profitability are not that conducive to run the business, in addition to staff turnover.

"My main challenge is low financial return and sustainability". (CS1, Manager)

"Our concerns are the high competition and expensive rent". (CS5, Community manager)

"Challenges reside in low profitability and high employee turnover as we employ undergraduate students and by the time they graduate they look for other jobs or we employ fresh graduates and once they have some work experience they leave for better jobs". (CS7, founder \& business developer)

Theme 10: The future of coworking spaces resides in being a significant component of the start-up ecosystem not just a place to rent offices or stations

The future vision of founders for coworking spaces is greatly affected by their ability to engage deeper with the start-up ecosystem as revealed from their comments:

"In Egypt, the culture of business incubators has begun to spread, it is very wise to collaborate with incubators and accelerators". (CS5, Community manager)

"My goal for the coming period is to develop and enhance my project to change the idea that coworking space is a place for private courses or studying only". (CS2, Owner \& managing director)

"Support for entrepreneurship and excellence". (CS3, Owner \& managing director)

\section{Discussions and conclusions}

The qualitative approach adopted in this research attempted to answer the following research questions:

First question: What are the different business models adopted?

This question is answered by the interviewees responses which revealed theme 1: Business Models are changeable to meet the market needs. Different business models exist from renting offices and stations to renting conference and training rooms. Also, some spaces generated revenue by providing 
consultancies and training programs to start-ups when they realized that generating revenue streams from just renting is not viable enough. Others modified their business model to be based on grants and funds with incubators and accelerators whether privately funded or by the government. This finding reinforces the claim of Knoll (2016) that although current coworking spaces vary in terms of business model, size, specialization and amenities, most are founded to accommodate individuals or groups that are not necessarily employed by a single organization, however users share certain values and are interested in the synergies which may occur from working with like-minded people in the same space. This research findings are also in congruence with Deskmag's (2019) that there are three or four successful business models for coworking spaces. Profits are often generated by renting desks, lockers, and conference rooms. The most common business model for coworking spaces is the one that generates revenue from membership fees for renting a workspace; another business model focuses on conference room rentals; adapting a conference room to serve multiple purposes. Conference rooms can be rented for business purposes, such as holding meetings, training staff, and video presentations, as well as for alternative social events.

Second question: What activities and events take place in coworking space in Egypt?

The answer to this question was revealed in theme 4: Interaction between members rarely takes place and theme 5: The community manager plays an important role to induce networking. The respondents articulated that social events such as: Ramadan Holly month meal (Iftar), games night and movies night are common activities in addition to, special events like monthly meeting for personal development sessions like work life balance... etc. or monthly breakfast \& birthday parties for our members. Holding workshops and training programs for start-ups are among the events that induce networking too. These research findings reinforce the findings of Capdevila (2014) which examined the dynamics of innovation involving coworking spaces in Barcelona and found that managers of coworking spaces, have an influence in facilitating collaborative practices among co-workers. In addition, Balakrishnan (2017) empirical findings from the qualitative phase revealed management support services provided by the coworking space enable the coworking members to operate their businesses efficiently. Huwart et al. (2012) highlighted that it is not just a workplace; it is more than sharing desks. Like-minded people get together, creating synergies, creative \& energetic spots, innovators interact, share, build, cocreate projects, and managers thrive to maintain a positive creative climate.

Third question: What challenges do the founders face in running coworking spaces?

The research findings revealed theme 9 that the major challenges are low financial return and high employee turnover and theme 10 that the future of coworking spaces resides in being a significant component of the start-up ecosystem not just a place to rent offices or stations. These findings are in congruence with the findings of the Research Group Collaborative Spaces (2016) which stipulated that despite the important role of coworking spaces in regional development and their positive externalities, many of these spaces are financially vulnerable and challenged by the significant financial burden they face in terms of running and maintenance costs (Moriset, 2014). According to Deskmag (2019) only 40\% of coworking spaces are profitable. In Egypt, coworking spaces do not only provide the physical space, but also host a lot of educational events such as workshops on entrepreneurship, finance, HR, and how to launch a business. A passionate investor with vision would set realistic pricing to succeed. Securing grants such as funds concentrated on supporting high-impact projects helps the coworking spaces to build their team and financially cover their operations. (American Chamber, 2018).

In conclusion, this paper presented an exploratory study tapping into the field of coworking space in the Egyptian context through conducting in-depth semi structured interviews with the owners/community managers of the coworking spaces and generating themes from the thematic analysis for the respondents' answers. The academic contribution relies in adding to the coworking space literature with respect to challenges faced in developing countries. The practical contribution resides in the recommendations such as better collaboration between coworking spaces and start-ups and the start-up ecosystem in general. In addition, studying the market in the neighborhood to identify the market need and type of customer is vital before embarking on the decision to establish a coworking space as an easy barrier to entry business. Community managers should capitalize on their presence on social media to 
promote better awareness about the benefits of networking and engagement among members as it is not just a place to study or perform tasks.

\title{
Limitations and direction for future research
}

The limitations of this research stem from the inability to cover the sample in different governorates in Egypt due to time and resources constraints. The convenient and small number of sample size hinders the findings to be confidently generalized to the population. These limitations stimulate further research that entails developing a conceptual framework for the coworking space dimensions preferred by the user and their impact on the users' loyalty. In addition, future research is needed to stand about the relation between the start-up ecosystem and coworking spaces. Deeper investigation into how coworking spaces can be of higher value to freelancers and part-time employees is also needed. Moreover, further research is required to provide solutions for coworking space owners to generate higher profitability and maintain sustainability and scalability of their business.

\author{
Appendix \\ Interview questions for founders/managers of Coworking spaces \\ Introduction \\ Please introduce yourself. Name, Job title, Age, Qualification, Gender. \\ How would you describe the business model of this coworking space? \\ Please describe sources of revenue.

\section{Customer} \\ Who are the customers of this coworking space? \\ How often do they visit this coworking space? \\ Interactivity \\ How would you describe the type of relationships between coworkers? \\ Do the users get to know each other or work in isolation? \\ Do you interfere to engage the users together? \\ What activities does the coworking space provide to encourage interaction among coworkers? \\ Design \\ Describe the design and atmosphere of this coworking space. \\ What does it promote? \\ Satisfaction and Loyalty \\ What are the factors that the customers require in order to be satisfied? \\ Do you measure customer satisfaction and feedback? If so, please elaborate. \\ Are there any loyalty programs/schemes/discounts? \\ Ending \\ What are the major challenges of managing coworking space? \\ Describe your vision for coworking space in the future. \\ Would you like to add anything regarding the topics we talked about?
}

\section{References}

American Chamber of Commerce in Egypt. (2018). Capturing the Rising Trend of Coworking Spaces. Retrieved on 30th May 2020 from: https://www.amcham.org.eg/publications/business-monthly/issues/272/August2018/3759/capturing-the-rising-trend-of-coworking-spaces

Balakrishnan, B. (2017). The effectiveness of an enriched servicescape framework on value-in-use and behavioral responses: the coworking space context. Doctoral Dissertation. School of Economics, Finance and Marketing, RMIT University.

Botsman, R. and R. Rogers. (2011). What's mine is yours: How collaborative consumption is changing the way we live. New York: Collins.

Braun, V. and Clarke, V. (2006). Using thematic analysis in psychology. Qualitative Research in Psychology, 3 (2). pp. 77-101. ISSN 1478-0887 Available from: http://eprints.uwe.ac.uk/11735

Brierley, H. (2012). 'Why Loyalty Programs Alienate Great Customers'.

Capdevila, I. (2014). "Different Inter-Organizational Collaboration Approaches in Coworking Spaces in Barcelona", in: SSRN Electronic Journal,

Coworking Resources. (2019). Ultimate Guide to Operating a Successful Coworking Space.

Deskmag. (2019). Coworking by the Numbers Results of the 2019 Global Coworking Survey

Deloitte. (2019). Emergence of co-working A Middle East Point of View

Enpact. (2019). Startup Ecosystem Report. V.1.0 
Fraering, M. and Minor, M. S. (2013). 'Beyond loyalty: Customer satisfaction, loyalty, and fortitude', Journal of Services Marketing, 27(4), pp. 334-344. doi: 10.1108/08876041311330807.

Gerdenitsch, S., Andorfer and Korunka. (2016). "Coworking spaces: A source of social support for independent professionals", in: Frontiers in Psychology, 7, pp. 1-12.

Huwart, J.-Y., Dichter, G. and Vanrie, P. (2012). Coworking: Collaborative Space for Microentrepreneurs (Technical Note \#1).

Knoll Workplace Research. (2016). The Rise of Co-working: A growing workplace movement

Leclercq-Vandelannoitte, A. and Isaac, H. (2016). 'The new office: how coworking changes the work concept', Journal of Business Strategy, 37(6), pp. 3-9. doi: 10.1108/JBS-10-2015-0105.

Moriset, B. (2014). "Building new places of the creative economy the rise of coworking spaces", in 2nd Geography of Innovation International Conference 2014 Utrecht University, Utrecht, 23- 25 January 2014, p. 24.

Mulas, V.; Minges, M.; Applebaum, H. (2015). Boosting Tech Innovation Ecosystems in Cities.

Parrino, L. (2015). "Coworking: assessing the role of proximity in knowledge exchange", in: Knowledge Management Research \& Practice, 13, pp. 261-271.

Rai, A. and Srivastava, M. (2012). 'Customer Loyalty Attributes: A Perspective', NMIMS Management Review, 22(November), pp. 49-76.

Research Group Collaborative Spaces. (2016). Coworkers, Makers and Hackers in the City: Reinventing Policies, Corporate Strategies and Citizenship?

Ressia, S. (2015). 'Neither Office Nor Home : Coworking As an Emerging Workplace Choice', 15(1), pp. 42-58.

Rus, A. and Orel, M. (2015). 'Coworking: A community of work', Teorija in Praksa, 52(6), pp. 1017-1038.

Sekaran, U. and Bougie, R. (2016). 'Research methods for business', Wiley, (SEPTEMBER), pp. 1-407.

doi: 10.13140/RG.2.1.1419.3126.

Tombs, A.G \& McColl-Kennedy, J.R. (2010). 'Social and spatial influence of customers on other customers in the social-servicescape', Australasian Marketing Journal, vol. 18, issue 3, pp. 120 - 31.

UNCTAD. (2017). ICT Policy Review: National E-Commerce Strategy for Egypt. 